\title{
Indian Medical Mission at Hajj-2016: Mass-Gathering Medicine Perspectives, Challenges, and Opportunities in a Mission Posture
}

\author{
Inam Danish Khan', Shazia Khan², Majid Ali Khan ${ }^{3}$, Muhammad Shaikhoo Mustafa ${ }^{4}$, MS Kidwai ${ }^{5}$, Shahbaz \\ Ali Khan', Bushra Asima ${ }^{6}$
}

${ }^{1}$ Army College of Medical Sciences and Base Hospital, New Delhi, India

${ }^{2}$ INHS Kalyani, Vishakhapatnam, India

${ }^{3}$ Command Hospital (EC), Kolkata, India

${ }^{4}$ Public Health Consultant, Chennai, India

${ }^{5}$ Director Medical Services, New Delhi, India

${ }^{6}$ Army Hospital Research and Referral, New Delhi, India

Corresponding Author: Inam Danish Khan, MD, DNB, Assistant Professor of Clinical Microbiology and Infectious Diseases, Army College of Medical Sciences and Base Hospital, New Delhi 110010, India. Tel: +91-9836569777, Fax: +91-11-25693490, Email: titan_afmc@yahoo.com

Received June 15, 2017; Accepted August 19, 2017; Online Published August 29, 2017

\begin{abstract}
Introduction: Hajj is an annual mass gathering of over 3.5 million pilgrims congregating from 200 countries in the desert climate of Saudi Arabia. Mass gathering medicine at Hajj is challenged by issues of healthcare accessibility, infection control, on-site treatment, referral, evacuation, and response to disasters and public health emergencies. The Indian Medical Mission at Hajj 2016 established, operated, and coordinated a strategic network of mass gathering medical operations, the proceeds of which are discussed herein.

Methods: The mission was designed to provide holistic health security through health intelligence for pre-existing chronic diseases, epidemic intelligence for endemic and exotic diseases, public-health and disaster-health preparedness, and tiered healthcare through mobile medical task forces, static clinics, tent clinics, secondary care hospitals, and evacuation capabilities.

Results: Primary care, secondary care, and tertiary care treated 374475, 930, and 523 patients, respectively. Patients exhibited limited compliance with pre-instituted treatments and precautionary protocols. Respiratory and gastrointestinal infections, cardiorespiratory, trauma, and heat illnesses were seen. Epidemic intelligence revealed an outbreak of food poisoning. Respiratory infections were reported by $90 \%$ of the healthcare personnel. Surge capacity was overwhelmed with patient throughput and ambulance transfers. Crude unadjusted mortality was 11.99/10000.

Conclusion: The Indian Medical Mission at Hajj 2016 yielded solutions to the challenges faced during the 2016 Hajj pilgrimage. The mission posture of the Indian Medical Mission in Hajj presents a modus operandi for handling crisis scenarios in mass gathering. The situational analysis of the Hajj health mission calls for dynamic interventions in preparedness, clientele, and health systems.

Keywords: Hajj, Mass Gathering Medicine, Travel Medicine, Public Health Preparedness, Disaster Health Preparedness, Medical Mission
\end{abstract}

Citation: Khan ID, Khan S, Khan MA, et al. Indian medical mission at Hajj-2016: mass-gathering medicine perspectives, challenges, and opportunities in a mission posture. Int J Travel Med Glob Health. 2017;5(3):94-101. doi:10.15171/ijtmgh.2017.20.

\section{Introduction}

Hajj is an annual mass gathering of over 3.5 million pilgrims from 200 countries who congregate in densities of 9 people/ $\mathrm{m} 2$ and endure strenuous rituals, compromised living standards, and a harsh desert climate in an alien ethnocultural and sociolinguist milieu for spiritual enlightenment. Mass gathering medicine at Hajj is challenged by issues of healthcare accessibility, infection control, on-site treatment, referral, evacuation, and response to disasters and public health emergencies in addition to challenges to providing support such as shelter, food and water, transportation, mass communication, interpersonal communication, sanitation, overcrowding, and human security. ${ }^{1,2}$

Hajj has historically experienced high morbidity and mortality owing to pre-existing comorbidities, outbreaks, accidents, and disasters such as such as stampedes, fires,

Copyright $\odot 2017$ The Author(s). This is an open-access article distributed under the terms of the Creative Commons Attribution License (http:// creativecommons.org/licenses/by/4.0), which permits unrestricted use, distribution, and reproduction in any medium, provided the original work is properly cited. 
construction collapse, violence, and transportation accidents, emphasizing the need for real-time surveillance and emergency response systems.,

Pre-existing cardiorespiratory and multisystem diseases lead to high morbidity and mortality during Hajj. ${ }^{5-8}$

While the outbreak of El Tor cholera during the 1905 Hajj is historic, the international outbreak of meningitis following the Hajj pilgrimages in 1987-1990, 1992, and 2000-2001 had serious repercussions. ${ }^{2,9,10}$ Surging troupes led to stampedes in 1990, 1994, 1998, 2001, 2003-06, and 2015 and resulted in the trampling-induced deaths of approximately 5100 pilgrims and injuries to 550 pilgrims. Major fire accidents in 1975, 1997, and 2011 led to 545 deaths and 1500 burn injuries. Violence has resulted in 569 deaths and polytrauma among thousands of pilgrims. Major construction collapses in 2006 and 2015 led to 194 deaths and 458 injuries. The death toll from transportation accidents exceeds $1500 .^{3,11,12}$

The meteoric growth in the number of Hajj pilgrims from 58000 in 1920 to 3160000 in 2012 has instigated novel challenges to the interdependent dimensions of health and human support systems. ${ }^{4,511,12}$ Saudi Arabia has reinvented Hajj management systems; nevertheless, the safety and security of pilgrims remains a national obligation of participating countries. Major countries fielding more than 100000 Hajj pilgrims annually, such as Indonesia (29000 pilgrims), Pakistan (180000 pilgrims), India (150000 pilgrims), and Egypt (125000 pilgrims), are obliged to operate medical contingents during the Hajj pilgrimage to address barriers of language, culture, and alienation in terra incognita. The Indian Medical Mission at Hajj 2016 was entrusted to establish, operate, and coordinate a strategic network of medical operations in Saudi Arabia. The current endeavor evaluated the Indian Medical Mission posture in mass gathering medicine at Hajj, its interoperability, and the gains thereof.

\section{Methods}

All 394013 patients presenting to the 2016 Indian Medical Mission at Mecca, Medina, or Jeddah in Saudi Arabia were included under an ambispective descriptive epidemiological study. The Indian Medical Mission undertook overall command, control, and coordination of health and hospital operations with a heterogeneous multidisciplinary multiorganizational medical team comprising 144 doctors, including 50 specialists, 146 paramedics, and 74 ancillaries. The mission was designed to provide holistic health security to 140000 Hajj pilgrims referring to the Indian Medical Mission through health intelligence, epidemic intelligence, public health and disaster health preparedness, medical attendance facilities, hospital operations, and philanthropic endeavors.

Health intelligence about pilgrims was gathered through pre-departure and post-arrival outreach screening for preexisting comorbidities, age above 70 years, addictions, treatment compliance, self-medication, and self-monitoring. Epidemic intelligence was collected through surveillance of locally endemic and exotic diseases having outbreak potential among pilgrims and patients. Interactions with multinational medical teams, the South Asian Moassasa (regional coordinating body), and Saudi Arabian hospitals were maintained. ${ }^{5,10}$ Public health preparedness was ensured through pre-departure mandatory immunoprophylaxis for meningococcus, tetanus, and influenza. Patient education posters and advisories regarding hand hygiene, respiratory precautions, food-water safety, social distancing, avoidance of exertion, dehydration, heat exposure, injuries, and infections were disseminated.

The mission area architecture was composed of a network of round-the-clock, tiered healthcare services. The various sectors of care included primary care static clinics, tent clinics, and mobile medical task forces; secondary care hospitals; and referral and evacuation capabilities at Mecca (Great mosque, Azizia, Mina, Arafat, and Muzdalifah), Medina, and Jeddah (a). Twenty-two static clinics with basic first-aid capabilities was prepared to accommodate $6000-9000$ pilgrims per clinic, extending medical services to 400 buildings in Mecca, Medina, and Jeddah, with onward referral to secondary care Indian hospitals $(b)$. Thirty-five tent clinics with medical attendance facilities only catered to $3000-4000$ pilgrims per clinic, extending medical services to a total of 5000 tents in Mina and Arafat as well as 1.4 million unsheltered pilgrims in Muzdalifah with onward referral to mobile referral tent clinics at Mina and Arafat or to hospitals of Saudi Arabia (c). Mobile medical task forces covered mass gathering congregations along the pilgrimage route and expected to have 5000-100 000 Indians. Onward referral was to secondary care Indian hospitals or tertiary care Saudi hospitals. Friday prayer congregations of approximately 4 million pilgrims were also covered by multinational medical teams for primary care and Saudi Arabia hospitals for secondary and tertiary care $(d)$. Capabilities were augmented through the establishment of 2 strategically positioned, makeshift 40bed secondary care Indian referral hospitals catering to 13 static clinics in Mecca and a 14-bed facility catering to five static clinics in Medina. Secondary care referral hospitals provided critical care, internal medicine, general surgery, orthopedics, gynecology, pediatrics, psychiatry, dermatology, isolation, lab-medicine, and radiology $(f)$. Tertiary care transfers by means of 16 ambulances were coordinated with 30 Saudi hospitals in Mecca, Medina, and Jeddah, and Indian translators were employed for Arabic to Indian language translation $(g)$. Medical mission personnel supervised the performance of Hajj rites and air evacuation thereafter to India for hospitalized and debilitated patients. The medical mission also extended philanthropic offerings of clothing, footwear, and other benevolent services throughout Hajj.

Medical facilities were established on the ground or mezzanine floors of rented buildings close to the pilgrim accommodations after licensure from the Ministry of Health of Saudi Arabia. Wheelchair ramps, signage, and patient-welfare personnel were employed for ease of access. Hospital diet, biomedical waste, and mortuary functions were outsourced to Saudi facilities. All equipment, medications, and consumables were provisioned from Indian manufacturers with supplemental procurement in Saudi Arabia.

Mission preparedness was evaluated through drills for high-throughput patient management, including medical 
attendance, laboratory-testing, imaging, medicationdispensing, minor procedures, admissions, and referrals. Standard operating procedures (SOPs) for various clinical, laboratory, inventory, administrative, and patient-safety algorithms were established. Disaster health preparedness was dynamically evaluated by situational analysis and scenario-based risk identification. Internal and external disaster preparedness including an incident-reporting system, facility evacuation, triage, life support, and patient transfer algorithms were rehearsed. Reports on medical attendance, bed-state, referrals, and deaths, including mandatory zero reporting, were forwarded through the daily medical and incident reporting systems. Retrospective data retrieved for trend analysis included more than 400000 annual patients from 2012-2015.

\section{Results}

The Indian Medical Mission 2016 catered to 394013 patients comprising 225,103 males (57.1\%) and 168,910 females (42.9\%) among 136,000 Indian pilgrims, non-Indian pilgrims, Indian and foreign expatriates totaling approximately 140000 during the Hajj season of 2016 (Table 1 and Table 2). Average medical usage rate was thrice per pilgrim during the 45-day stay of pilgrims in Saudi Arabia. Low acuity complaints comprised 93\% of outpatients. Three-fourths of all hospitalizations and referrals were high acuity demanding resource-intensive efforts. Total secondary care bed days were 2106, and average bed occupancy was $77.78 \%$ for 30 days prior and 15 days after Hajj and $32 \%$ otherwise. Pooled unadjusted average length of stay of all patients was 3.6 days.

Pilgrims underwent the recommended immunizations and abstained from alcohol and recreational drugs; however, they did not refrain from consuming tobacco. Limited compliance of instituted treatment and precautionary protocols such as dietary precautions, respiratory precautions, sun-protection, hand hygiene, contact avoidance and social distancing, and limited self-monitoring of blood pressure and glucose levels existed. Analgesic abuse and self-medication was common, although some pilgrims were not traveling with adequate quantities of prescribed medicines for chronic diseases. Some of the 13255 (9.75\%) elderly (above 70 years of age) and 483 $(0.35 \%)$ pilgrims having pre-existing comorbidities preferred wheelchair-aided mobility. There were 2 differently-abled diabetic pilgrims with leg amputations.

Infectious diseases affecting respiratory and gastrointestinal systems were commonly seen along with non-infectious cardiorespiratory, urogenital, and trauma-related problems. Heat illness was commonly seen in tent clinics. Thirty-three malaria cases were treated using arteether, pyrimethamine, and sulphadoxine. Among all patients, 29.2\% were hospitalized for gastrointestinal diseases followed by $20.9 \%$ for respiratory diseases. Out of 12 cases of discharge against medical advice and three cases of leave against medical advice, seven cases had to be re-hospitalized. A total of 337 males (68.10\%) and 158 females (46.90\%) were hospitalized in tertiary care Saudi hospitals. Most referrals were done for cardiovascular diseases (27.10\%) followed by orthopedics (16.80\%), and $87.42 \%$ of pharmaceutical inventory on demand was received for patient care. Analgesics, antipyretics, antimicrobials, antacids, oral antidiabetics, antihypertensives, antihistamines, and antitussives were most commonly prescribed. Mean BMW generation for in-patients was $2.1 \mathrm{~kg} / \mathrm{d}$ (4254 kg).

Epidemic intelligence for exotic diseases such as Ebola, Middle-East respiratory syndrome (MERS), Alkhumra viral hemorrhagic fever, Rift Valley fever, and Zika resulted in zero reported cases. No cases of endemic diseases such as dengue, polio, rabies, or leishmaniasis were encountered, however transmission could not be conclusively negated. Cases of influenza, malaria, dengue and Hepatitis A may have gone undiagnosed. There was a public health incident of Staphylococcus aureus food poisoning from communal food affecting 90 pilgrims. A bus fire resulted in four firstdegree burn patients, however a building fire and a structural collapse were fortunately without any casualties. Along with pilgrims, $90 \%$ of healthcare professionals (HCPs) reported cough and sore throat at least twice during the mission, despite good respiratory and hand hygiene compliance, requiring antimicrobial administration without hospitalization.

Massive surges of patients reaching 1500-2000 per day at static clinics overwhelmed the throughput capability. Patients desiring outpatient attendance, pharmacy, laboratory, imaging, ambulance, and referral services experienced long hours of waiting due to high densities after namaz prayers. Ambulances encountered delays due to reorganized routes

Table 1. Indian Medical Mission Demographics for Hajj pilgrims From 2012 to 2016

\begin{tabular}{|c|c|c|c|c|c|}
\hline Year & 2016 & 2015 & 2014 & 2013 & 2012 \\
\hline \multicolumn{6}{|c|}{ Distribution of Patient Clientele } \\
\hline Indian pilgrims & 393083 & 400975 & 418136 & 435380 & 425218 \\
\hline Indian officials/workers & 458 & 502 & 431 & 444 & 490 \\
\hline Non-Indian pilgrims & 45 & 63 & 56 & 34 & 30 \\
\hline Saudi Arabian citizens & 190 & 172 & 191 & 283 & 267 \\
\hline Non-Indian citizens & 237 & 584 & 694 & 1329 & 1498 \\
\hline Total & 394013 & 402296 & 419508 & 437470 & 427503 \\
\hline \multicolumn{6}{|c|}{ Population Demography of Indian Hajj Pilgrims } \\
\hline Deaths amongst Indian pilgrims & 163 & 311 & 149 & 177 & 254 \\
\hline Births amongst Indian pilgrims & 4 & 12 & 8 & 13 & 6 \\
\hline
\end{tabular}


Table 2. Indian Medical Mission Operations for Hajj Pilgrimage From 2012-2016

\begin{tabular}{|c|c|c|c|c|c|}
\hline Year & 2016 & 2015 & 2014 & 2013 & 2012 \\
\hline \multicolumn{6}{|c|}{ Outreach Health Screening } \\
\hline Age $70-100$ years & 13255 & 13231 & 13262 & 20518 & 7367 \\
\hline Age $>100$ years & 2 & 3 & 3 & 6 & 5 \\
\hline Pilgrims with chronic diseases & 483 & 645 & 591 & 521 & 634 \\
\hline \multicolumn{6}{|c|}{ Primary Care } \\
\hline Outpatients - Static Clinics & 374475 & 379791 & 402407 & 417668 & 401890 \\
\hline Outpatients - Tent Clinics & 5135 & 8405 & 4908 & 4736 & 4680 \\
\hline Mobile Task Force patients & 13473 & 13003 & 11358 & 14199 & 20012 \\
\hline \multicolumn{6}{|c|}{ Secondary Care } \\
\hline Secondary care referrals & 930 & 1097 & 835 & 867 & 921 \\
\hline Secondary care hospitalizations & 585 & 678 & 665 & 626 & 601 \\
\hline \multicolumn{6}{|c|}{ Tertiary Care } \\
\hline Tertiary care referrals & 523 & 578 & 458 & 491 & 439 \\
\hline Tertiary care hospitalizations & 495 & 565 & 421 & 454 & 415 \\
\hline \multicolumn{6}{|c|}{ Procedures } \\
\hline Minor general surgery procedures & 1505 & 1243 & 1155 & 912 & 979 \\
\hline Orthopedic procedures & 770 & 521 & 446 & 418 & 402 \\
\hline \multicolumn{6}{|c|}{ Investigations } \\
\hline Laboratory investigations & 7850 & 6734 & 4367 & 3063 & 2536 \\
\hline Imaging & 2074 & 1853 & 1733 & 1626 & 2189 \\
\hline Electrocardiogram & 1159 & 1094 & 922 & 798 & 642 \\
\hline \multicolumn{6}{|c|}{ Evacuation } \\
\hline Evacuation - sitting patients & 5 & 16 & 11 & 9 & 12 \\
\hline Evacuation - Iying patients & 6 & 4 & 3 & 4 & 2 \\
\hline \multicolumn{6}{|c|}{ Incident Reporting System for Indian Hajj Pilgrims } \\
\hline Road traffic accidents & 10 & 12 & 8 & 13 & 6 \\
\hline Other incidents & 14 & 168 & 12 & 18 & 22 \\
\hline
\end{tabular}

and heavy vehicle and pedestrian traffic. There was also a delay in attendance, suspicion, diagnosis, and isolation of patients with communicable infections. Accessibility issues were seen with mezzanine floors due to long waiting times for elevators for patients in wheelchairs. Overwhelming numbers of cases of heat illness in tent clinics were administered parenteral fluids on couches or chairs due to the unavailability of beds.

Pilgrims were highly distressed because of anxiety, extreme heat, overcrowding, physical exertion, dehydration, language barriers, tough living conditions, and being in a foreign environment. Most patients did not bring old prescriptions, and this led to improper treatment and follow-up. Pilgrims brought after being lost in crowds and unable to seek help by themselves had to be escorted to their tents/rooms. In a multicultural, multilingual, and multiracial environment, patients were treated with humanity, neutrality, impartiality, and patience, while the security and decorum of the facility were maintained; patients were ensured of receiving the best possible standards of healthcare. The possibility of pilgrims being lost to follow-up was covered by aggressive therapy including empirical antimicrobials.

Twenty-two pilgrims were escorted through the performance of the Hajj rites by medical mission personnel. Out of 11 patients air evacuated from Mecca to their residences in India, 6 were on stretchers, 5 were in wheelchairs, and 2 were provided in-flight oxygen under the supervision of medical mission personnel. Crude unadjusted mortality among pilgrims was $11.99 / 10000$ in 2016 compared to $27.02 / 10000$ in 2015. Out of 163 deaths, 112 were males and 51 were females. The most common fatal event was cardiorespiratory arrest. Risk factors associated with high morbidity were old age and pre-existing comorbidities. One medicolegal proceeding in a road-traffic accident and two autopsies to ascertain cause of death were performed in Saudi-Arabian facilities.

\section{Discussion}

Mass gathering medicine is a challenging field of pre-hospital care in emergency medicine that explores the health effects/ risks of mass gatherings and the strategies that contribute positively to effective healthcare delivery during these events. Mass gathering medicine involves higher rates of morbidity and mortality attributable to infections, trauma, environment, occupation, lifestyle, substance abuse, and disasters., ${ }^{4,5,13,14}$ Astute preparedness is imperative across critical policy arenas bearing direct snowballing connotations to the number of casualties. The Sendai Framework gives a mandate for disaster risk reduction (DRR) in mass gatherings. ${ }^{10}$

The Indian Medical Mission executed an innovative Hajj medical mission for approximately 400000 patients incorporating a patient-centric systems approach across the various operations of health intelligence, public-health measures, task forces, clinics, hospitals, evacuations, and 
non-medical philanthropy in a stringent mission posture and dedication to self-actualization levels. The doctor:patient and paramedic:patient ratios in Indian, Thailand, and Malaysian Hajj medical missions were approximately 1:944 and 1:931, $1: 250$ and $1: 950$, and $1: 320$ and 1:140, respectively. The average age of Thai and Malaysian Hajj pilgrims was less than that of Indian pilgrims. The ambulance:patient ratios for India and Malaysia were 1:9300 and 1:2400, respectively. These figures highlight the operational stringency of the Indian Medical Mission.

Approximately 36\%-40\% of pilgrims attempt Hajj with multiple comorbidities and often with poor treatment and precautionary compliance. Thus, they face serious complications or polymicrobial infections mandating tertiary care referrals and/or evacuation from Saudi Arabia to their residence in India. ${ }^{15-18}$ The average length of secondary care admission was 3.6 days. ${ }^{19-21}$

Healthcare for pilgrims from all countries is completely sponsored by Saudi Arabia through 141 Hajj medical centers and 100 ambulances; however, there are limitations in bed availability, ambulance transfers, and the daily follow-up of transferred patients. ${ }^{5,11,22}$

Trend analysis from 2012 to 2016 revealed a modest decrease in patient attendance, largely attributable to the increase in self-care for chronic comorbidities. Mortality among Indian Hajj pilgrims is largely attributable to patientspecific causes comparable with pilgrims of other countries because of the large geriatric population with pre-existing health conditions. ${ }^{18}$ Environment-specific mortality is caused by heat illness, and incident-specific mortality may be due to incidents and disasters. ${ }^{3-5,23}$

Emerging diseases such as Ebola, MERS, Alkhumra viral hemorrhagic fever, Rift Valley fever, and unidentified imported diseases having intercontinental implications challenge global public health security during Hajj. ${ }^{1,15,18}$ Overcrowding increases the risk of transmission of respiratory pathogens such as human rhinovirus, respiratory syncytial virus, MERS and non-MERS Corona virus (229E, HKU1, NL63, OC43), influenza A H1N1, influenza B, adenovirus, multidrug resistant tuberculosis (MDRTB), and Streptococcus pneumoniae in an environment of "Hajj cough" in mass gathering Hajj rituals. ${ }^{5,10,16,17,19,24}$ A significant difference has been seen in pre- and post-Hajj carriage rates of Influenza $\mathrm{A}$ and $\mathrm{B}$, rhinovirus, and non-MERS coronaviruses. Five fatalities were reportedly caused by Influenza A H1N1 among less than one hundred patients during Hajj 2010. ${ }^{17,25}$ While one-fifth of hospitalized patients acquired $\mathrm{H} 1 \mathrm{~N} 1$ outside Saudi Arabia, the confirmed cases represent the tip of the iceberg in a pandemic scenario. ${ }^{17}$ Undiagnosed and untreated active, subclinical, and latent MDRTB cases from endemic high burden world regions remain serious health hazards as tuberculosis is the leading cause of mortality from an infectious disease worldwide. ${ }^{5,10,26-28}$ Neisseria meningitidis W135 outbreaks in 2000 and 2001 during Hajj were followed by a global spread, a risk existing for all MDR bacteria. ${ }^{2,3,5,13,25,29,30}$

Hajj is the only mass gathering that has instituted mandatory immunoprophylaxis for pilgrims, pilgrim contacts, HCPs, and the local population. ${ }^{2,3,5}$ Elements protecting against outbreak include limited contact with zoonotic, environmental, and community reservoirs despite the ritual of animal sacrifice during Hajj; the vaccination status of pilgrims and the local population; and the transient stay of pilgrims preventing multiple generations of transmission. Influenza vaccination of pilgrims in their home countries may not be effective as vaccines are derived from different strains in the northern and southern hemispheres. ${ }^{2}$ Nevertheless, clinical suspicion increases the burden of laboratory testing, and institutionalization furthers healthcare-associated transmission. ${ }^{21,31,32}$

With the Middle East catering to 10 million annual pilgrims and otherwise being a global transport hub, travel-related infections and public health emergencies need to be assessed, detected, and answered with robust health systems under a One-Health approach in consonance with international health regulations. ${ }^{3,5,13,33,34}$ Quarantine, syndromic surveillance, and cluster investigation for endemic infectious diseases including dengue and Rift Valley fever can be feasible primary tools for mass gatherings during Hajj. ${ }^{35,36}$ The prohibition of pilgrims from Liberia, Guinea, and Sierra Leone led to zero Ebola cases during Hajj 2015. Two MERS hospitalizations and zero deaths were reported during Hajj 2014. ${ }^{15}$

Hajj also has the distinction of having the best mass gathering preparedness effort in the world; nevertheless, the history of Hajj is replete with disasters and accidents leading to mass mortality. ${ }^{37}$ Mass gathering medicine at Hajj is backed by robust public health policies encompassing a multi-sectoral risk mitigation, intervention, coordination, cooperation, and communication strategy in international dimensions. ${ }^{13}$ Mass gathering medicine as a discipline was formally launched by the World Health Assembly of Ministers in Geneva in May, 2014 after the Jeddah declaration at the global forum on ass gathering medicine in 2010 in Saudi Arabia. Saudi Arabia has boosted infrastructure and logistics while reducing the number of pilgrims for Hajj from 5 million to 3.5 million to further reduce the scale of one pilgrim per 1000 Muslim population per country, and Indian pilgrims from 2.5 million to 1.36 million in 2016 accordingly, for better control of situational complexities. ${ }^{3-5}$ Saudi Arabia's disaster preparedness includes human, technical, and aerial surveillance aided by the Saudi armed forces during Hajj. DRR measures have been adopted through alterations in space, scope, and time; crowd control; ingress and egress. Despite these measures, pilgrims are likely to get separated and lost in crowds because of the improper/ not visible signage, missed trains, poor visibility, and lack of knowledge of places, languages, and authorities. They may not be able to return due to physical, psychological, personal and financial limitations. No shelter in Muzdalifah and 50100 pilgrims per tent in 45000 tents in Mina pose problems associated with environmental exposure, overcrowding, food safety, and hygiene. Preparedness against chemical, biological, and radio-nuclear agents includes a stockpile of smallpox vaccine and the availability of Saudi military expertise. ${ }^{5,22}$ Food and water are heavily regulated by the Saudi Food and Drug authority; however, risks exist due to the makeshift cooking areas, lack of refrigeration, and culinary practices in tents. 
Unidentified mortal remains collected by Saudi authorities are difficult to retrieve from Saudi mortuaries because of a lack of identification data. All unnatural incident victims are compensated through group insurance. ${ }^{36}$

Preventive health, leadership, quality initiatives, and preparedness could only be assessed subjectively. A centerstaged culture of enhanced multidisciplinary synergy, critical-thinking, and disaster health preparedness prevailed among all medical mission personnel. Despite the primary operations of health security being overwhelmed by patient load, the agility, presence, reliability, and philanthropy were found appealing by the clientele and critics, and accordingly applauded by local media. ${ }^{3-5}$ The overwhelming number of patients may lead to a downgrading of medical centers to resource-limited setups, but this would compromise the standards of healthcare, clientele satisfaction, and resource security. It may also lead to physical, mental, and compassion fatigue among healthcare personnel. ${ }^{5,38}$ The mission posture mandates an effective team focused on goals, roles, and procedures for improved cognitive, affective, process, and performance outcomes.

The situational analysis of the Hajj health mission called for dynamic interventions in preparedness, clientele, and health systems on parallel fronts.

Infrastructural, logistic, and supply-chain interventions such as locating hospitals and clinics on ground floors instead of mezzanine floors and away from traffic zones, the incorporation of expansion capacity for contingencies, better heating-ventilation-air conditioning (HVAC), CCTV, intercom network, and the separation of health facilities from pilgrim accommodations are required. Capacity augmentation through increasing bed strength to 60 , four intensive care and cardiac care beds, a minor operation theater, 50 ambulances, and a mortuary for 2 bodies to address unanticipated delays are desirable. Hospital equipment, consumables, and personnel should be accommodated in the same building for rapid emergency response. Ambulance traffic, communication, and network optimization between task forces, clinics, and hospitals are required for patient transfer, information, and telemedicine interoperability. ${ }^{13,14}$

Human resource interventions require the region- or statewise pro rata deputation of 150 doctors and 200 paramedics; and better move assistance and accommodation of medical, paramedical, counseling, and administrative officials. A post-induction training program on life support, patient safety, mass gathering medicine, crowd control, and disaster management is desirable. $3,5,39$

Quality and preparedness interventions should incorporate pneumococcal vaccinations for the elderly; objective scoring systems such as the Acute Physiology and Chronic Health Evaluation IV for elderly pilgrims; third party medical audits for resources, protocols, patient comfort and security; facility worthiness for geographic, social, environmental, and technological phenomena; and evaluation of contingency plans. ${ }^{15,40,41}$

Clientele interventions targeted at patient education towards choosing to perform Hajj at a younger age, self-

\section{Research Highlights}

\section{What Is Already Known?}

Mass-gathering medicine at Hajj is plagued by issues of healthcare accessibility, on-site treatment, evacuation, response to disasters and public-health emergencies; emanating challenges in interdependent dimensions of health and human support systems.

\section{What This Study Adds?}

1. The Indian Medical Mission represents a modus operandi for mass-gathering medicine through health intelligence for pre-existing diseases, epidemic intelligence for endemic/exotic diseases, public-health and disasterhealth preparedness, and tiered healthcare infrastructure. 2. High transmissibility of respiratory infections can increase admissions and spread, thereby overwhelming costs and eventual globalization of multiresistant pathogens.

triage based on chronic comorbidities, fluid intake, food hygiene, avoiding handshakes, carrying previous records for subsequent visits, avoiding self-medication, treatment compliance, and understanding tiered health systems are mandated. ${ }^{19,24}$ Behavioral modification and counseling about infection control, health precautions, and expectations need to be incorporated in modern healthcare systems to ensure future standards of healthcare. ${ }^{41}$ Clientele assessments and engagement can be fostered by new-age, technology-driven Delphi techniques through smartphone platforms for early reporting and passive surveillance. ${ }^{31,32}$

Health system interventions such as evidence-based surveillance systems including real-time and post-event surveillance, disaster decision support-systems, crossplatform wireless records systems, political patronage, legislative drug dispensing by local pharmacies, and capability assurance towards mass gathering medicine and travel medicine can facilitate the operational fecundity of various stakeholders. ${ }^{13,14,21,29}$

The magnitude of the Hajj medical operations calls for a permanent Indian civil hospital sited near the Indian Hajj pilgrim office, directed by a medical specialist to oversee planning, operations, and coordination throughout the Hajj paradigm and be suspended in the lean period. The permanent incumbent for Hajj medical operations should be a specialist doctor with experience in healthcare administration..$^{22}$ A field hospital on wet induction can be deployed to enhance the contingency, incorporating intrepidity and resilience towards disasters, especially in the interim period.

\section{Conclusion}

The Indian Medical Mission at Hajj 2016 presented solutions to challenges faced during the 2016 Hajj pilgrimage. The Indian Medical Mission posture in a foreign country elucidates a modus operandi for mass gathering medicine perspectives, challenges, and opportunities for planning and executing philanthropic medical missions catering to situations of 
exigency. The mission emphasizes a strategic, tactical, and operational structure through technical expertise, dynamic leadership and team building, strategic planning and foresight, resource optimization, health and epidemic intelligence, case and casualty management, infection control, interoperability, disaster, and emergency and crisis preparedness applicable to mass gatherings such as religious pilgrimages, social events, sporting events, music concerts, fests, corteges, political rallies, and migrants displaced by conflict, disaster, or war.

\section{Authors' Contributions}

All authors contributed equally to this study.

\section{Conflict of Interest Disclosures}

None.

\section{Ethical Approval}

Ethical approval was covered by Institutional Committee.

\section{Funding/Support}

None.

\section{References}

1. Memish ZA, Stephens GM, Steffen R, Ahmed QA. Emergence of medicine for mass gatherings: lessons from the Hajj. Lancet Infect Dis. 2012;12(1):56-65. doi:10.1016/s1473-3099(11)70337-1

2. Shujaa A, Alhamid S. Health response to Hajj mass gathering from emergency perspective, narrative review. Turk J Emerg Med. 2015;15(4):172-176. doi:10.1016/j.tjem.2015.02.001.

3. Manoochehry S, Rasouli HR. Recurrent human tragedy during Hajj. Int J Travel Med Glob Health. 2017;5(1):36-37. doi:10.15171/ ijtmgh.2017.07.

4. Ganjeh M, Einollahi B. Mass Fatalities in Hajj in 2015. Trauma Mon. 2016;21(5):e43253. doi:10.5812/traumamon.43253.

5. Khan ID, Khan SA, Asima B, Hussaini SB, Zakiuddin M, Faisal FA. Morbidity and mortality amongst Indian Hajj pilgrims: a 3-year experience of indian Hajj Medical Mission in massgathering medicine. J Infect Public Health. 2017. doi:10.1016/j. jiph.2017.06.004.

6. Khan NA, Ishag AM, Ahmad MS, El-Sayed FM, Bachal ZA, Abbas TG. Pattern of medical diseases and determinants of prognosis of hospitalization during 2005 Muslim pilgrimage Hajj in a tertiary care hospital. A prospective cohort study. Saudi Med J. 2006;27(9):1373-1380.

7. Alzahrani AG, Choudhry AJ, Al Mazroa MA, Turkistani AH, Nouman GS, Memish ZA. Pattern of diseases among visitors to Mina health centers during the Hajj season, $1429 \mathrm{H}$ (2008 G). J Infect Public Health. 2012;5(1):22-34. doi:10.1016/j.jiph.2011.10.003.

8. Mandourah Y, Ocheltree A, Al Radi A, Fowler R. The epidemiology of Hajj-related critical illness: lessons for deployment of temporary critical care services. Crit Care Med. 2012;40(3):829-834. doi:10.1097/CCM.0b013e318236f49b.

9. Yezli S, Assiri AM, Alhakeem RF, Turkistani AM, Alotaibi B. Meningococcal disease during the Hajj and Umrah mass gatherings. Int J Infect Dis. 2016;47:60-64. doi:10.1016/j. ijid.2016.04.007.

10. Zumla A, McCloskey B, Bin Saeed AA, et al. What is the experience from previous mass gathering events? Lessons for Zika virus and the Olympics 2016. Int J Infect Dis. 2016;47:1-4. doi:10.1016/j. ijid.2016.06.010.

11. Timeline: Annual pilgrimage frequently struck by disaster. The New York Times. January 12, 2006. https://mobile.nytimes. com/2006/01/12/world/africa/timeline-annual-pilgrimagefrequently-struck-by-disaster.html

12. Hajj stampede: At least 717 killed in Saudi Arabia. BBC News,
Middle East. 2015. https://www.bbc.com/news/world-middleeast-34346449.

13. Kollek D. An intro to mass gatherings. Centre for Excellence in Emergency Preparedness. Ontario-Canada. June 2014. http:// www.ceep.ca/publications/Mass_Gatherings.pdf.

14. WHO. Epidemic and Pandemic Alert and Response. Communicable Disease alert and response for mass gatherings. WHO/HSE/ EPR/2008/8 Technical Workshop. Geneva-Switzerland: WHO; 2008:1-29. http://www.who.int/csr/mass_gathering/en/.

15. Memish ZA, Assiri A, Turkestani A, et al. Mass gathering and globalization of respiratory pathogens during the 2013 Hajj. Clin Microbiol Infect. 2015;21(6):571.e571-e578. doi:10.1016/j. cmi.2015.02.008.

16. Razavi SM, Sabouri-Kashani A, Ziaee-Ardakani $\mathrm{H}$, et al. Trend of diseases among Iranian pilgrims during five consecutive years based on a Syndromic Surveillance System in Hajj. Med J Islam Repub Iran. 2013;27(4):179-185.

17. Haworth E, Rashid H, Booy R. Prevention of pandemic influenza after mass gatherings - learning from Hajj. J R Soc Med. 2010;103(3):79-80. doi:10.1258/jrsm.2010.090463.

18. Pane M, Imari S, Alwi Q, Nyoman Kandun I, Cook AR, Samaan G. Causes of mortality for Indonesian Hajj Pilgrims: comparison between routine death certificate and verbal autopsy findings. PLoS One. 2013;8(8):e73243. doi:10.1371/journal.pone.0073243.

19. Razavi SM, Mohazzab Torabi S, Salamati P. Treatment and prevention of acute respiratory infections among Iranian hajj pilgrims: a 5-year follow up study and review of the literature. Med J Islam Repub Iran. 2014;28:31.

20. Shirah BH, Zafar SH, Alferaidi OA, Sabir AMM. Mass gathering medicine (Hajj Pilgrimage in Saudi Arabia): the clinical pattern of pneumonia among pilgrims during Hajj. J Infect Public Health. 2017;10(3):277-286. doi:10.1016/j.jiph.2016.04.016.

21. Khan ID, Basu A, Kiran S, Trivedi S, Pandit P, Chattoraj A. Deviceassociated healthcare-associated infections (DA-HAI) and the caveat of multiresistance in a multidisciplinary intensive care unit. Med J Armed Forces India. 2017;73(3):222-231. doi:10.1016/j. mjafi.2016.10.008.

22. Benkouiten S, Charrel R, Belhouchat K, et al. Respiratory viruses and bacteria among pilgrims during the 2013 Hajj. Emerg Infect Dis. 2014;20(11):1821-1827. doi:10.3201/eid2011.140600.

23. Al-Asmary S, Al-Shehri AS, Abou-Zeid A, Abdel-Fattah M, Hifnawy T, El-Said T. Acute respiratory tract infections among Hajj medical mission personnel, Saudi Arabia. Int J Infect Dis. 2007;11(3):268272. doi:10.1016/j.ijid.2006.04.008.

24. Gautret P, Benkouiten S, Griffiths K, Sridhar S. The inevitable Hajj cough: Surveillance data in French pilgrims, 2012-2014. Travel Med Infect Dis. 2015;13(6):485-489. doi:10.1016/j. tmaid.2015.09.008.

25. Al-Tawfiq JA, Zumla A, Memish ZA. Respiratory tract infections during the annual Hajj: potential risks and mitigation strategies. Curr Opin Pulm Med. 2013;19(3):192-197. doi:10.1097/ MCP.0b013e32835f1ae8.

26. Jindal AK, Pandya K, Khan ID. Antimicrobial resistance: A public health challenge. Med J Armed Forces India. 2015;71(2):178-181. doi:10.1016/j.mjafi.2014.04.011.

27. Akbar S. Indian Hajis have highest mortality rate, says study. Times of India, July 12, 2017. http://timesofindia.indiatimes.com/city/ hyderabad/indian-hajis-have-highest-mortality-rate-says-study/ articleshow/59555244.cms.

28. Akbar S. Majority Indians hospitalized in Mecca, Medina during Haj in 70-90 age group. Times of India, July 12, 2017. http:// timesofindia.indiatimes.com/city/hyderabad/majority-indianshospitalized-in-mecca-medina-during-haj-in-70-90-age-group/ articleshow/59555251.cms.

29. Khan ID, Sahni AK. Rapid diagnosis of dengue outbreaks in resource limited facilities. West Indian Med J. 2017;66(1). doi: 10.7727/wimj.2016.095.

30. Khan ID, Dogra PM, Ramphal SK,et al. Polymicrobial infections in a teenaged Renal Transplant Recipient. J Basic Clin Med. 
2015:4(1):37-39.

31. Khan ID, Gupta N, Rangan NM, et al. Evaluation of pre and post analytical variables in clinical microbiology services in multidisciplinary ICU of a medical college and tertiary care hospital. J Basic Clin Med. 2016;5(1):2-4.

32. Alhaeli A, Bahkali S, Ali A, Househ MS, El-Metwally AA. The epidemiology of Dengue fever in Saudi Arabia: a systematic review. J Infect Public Health. 2016;9(2):117-124. doi:10.1016/j. jiph.2015.05.006.

33. Sahni AK, Singh SP, Kumar A, Khan ID. Comparison of IS6110 and 'short fragment' devR (Rv3133c) gene targets with phenotypic methods for diagnosis of Mycobacterium tuberculosis. Med J Armed Forces India. 2013;69(4):341-344. doi:10.1016/j. mjafi.2013.02.003.

34. Khan ID, Sahni AK, Bharadwaj R, Lall M, Jindal AK, Sashindran VK. Emerging organisms in a tertiary healthcare set up. Med J Armed Forces India. 2014;70(2):120-128. doi:10.1016/j. mjafi.2013.09.005.

35. Khan ID. Challenges and opportunities in diagnosis and management of infectious diseases in developing country healthcare system. J Basic Clin Med 2016;5(1):1.

36. Hutton A, Brown S, Verdonk N. Exploring culture: audience predispositions and consequent effects on audience behavior in a mass-gathering setting. Prehosp Disaster Med. 2013;28(3):292297. doi:10.1017/s1049023×13000228.

37. Khan ID, Asima B, Khan SA. Operations throughput as a determinant of golden-hour in mass-gathering medicine. Int J Med and Med Res. 2017;3(1):52-58. doi:10.11603/JJMMR.2413-6077.2017.1.7804.

38. AI-Ghamdi AS, Kabbash IA. Awareness of healthcare workers regarding preventive measures of communicable diseases among Hajj pilgrims at the entry point in Western Saudi Arabia. Saudi Med J. 2011;32(11):1161-1167.

39. Pan American Health Organization, World Health Organization. Hospital Safety Index: Evaluation Forms for Safe Hospitals. Washington, DC: Emergency Preparedness and Disaster Relief, PAHO; 2008

40. Madani TA, Albarrak AM, Alhazmi MA, Alazraqi TA, Althaqafi AO, Ishaq AH. Steady improvement of infection control services in six community hospitals in Makkah following annual audits during Hajj for four consecutive years. BMC Infect Dis. 2006;6:135. doi:10.1186/1471-2334-6-135.

41. Turkestani A, Balahmar M, Ibrahem A, Moqbel E, Memish ZA. Using health educators to improve knowledge of healthy behaviour among Hajj 1432 (2011) pilgrims. East Mediterr Health J. 2013;19 Suppl 2:S9-S12. 